\title{
24. A MAGNETIC SUSCEPTIBILITY STRATIGRAPHY FOR PLEISTOCENE AND PLIOCENE SEDIMENTS IN THE VICINITY OF THE BARBADOS RIDGE ${ }^{1}$
}

\author{
M. W. Hounslow 2,3
}

\begin{abstract}
Whole-core magnetic susceptibility measurements define a detailed stratigraphy that enables correlation between the various Pleistocene, Pliocene, and upper Miocene sections cored on ODP Leg 110, near the Tiburon Rise. The magnetic susceptibility in these sections is primarily related to the content of volcanic ash, rich in titanomagnetite, and also inversely related to calcium carbonate content. The high resolution of the susceptibility record enables correlations with a resolution of about $0.3 \mathrm{~m}$ of sediment thickness, and the identification of minor faults not definable by biostratigraphic means. Reverse and normal faults identified in Hole $672 \mathrm{~A}$ are probably a result of normal oceanic sediment dewatering and compaction processes. This work indicates some of the problems of using visible ash layers as time-stratigraphic markers.
\end{abstract}

\section{INTRODUCTION}

The magnetic susceptibility of sediment is primarily indicative of the content of magnetic minerals, but also of the grain size and composition of this magnetic material. Magnetic susceptibilty is easily determined, which has resulted in its widespread use, with other mineral/rock magnetic parameters, as an environmental indicator and as a means of characterizing sediment sources (Thompson and Oldfield, 1986; Hilton, 1987; King et al., 1982). It has also been used in detailed stratigraphic correlation in lakes and oceanic sediments (Robinson, 1982; Thompson et al., 1980).

The Pleistocene to Miocene sediments recovered on ODP Leg 110 contain abundant volcanic ash derived from the Lesser Antilles volcanic arc (Mascle, Moore, et al., 1988). The hemipelagic sedimentation and the abundant volcanogenic ash-fall layers provided an ideal opportunity to use magnetic susceptibility for detailed core correlation linked to a biostratigraphic framework.

The location of the ODP Leg 110 sites are indicated in Figure 1. The sediments recovered on Leg 110 range from Pleistocene and Pliocene calcareous clay and mud to cyclic alternations of clay, limestone, and sand in the upper and middle Eocene. The Miocene section is dominated by mudstones, in part radiolarian rich, and the Oligocene by mudstones and calcareous claystones.

\section{METHODS}

Magnetic susceptibility was determined on the JOIDES Resolution using a Bartington whole-core susceptiblity meter (prior to core splitting, and after GRAPE and thermal conductivity measurements). The instrument was calibrated using a $\mathrm{MnO}_{2}$ standard of the same diameter as the core. Measurements were undertaken at either 5-, 10-, or sometimes $20-\mathrm{cm}$ spacing, starting at the measurement spacing distance from the core-section top. A spacing of $5 \mathrm{~cm}$ was used on the APC cores, whereas 10-cm spacing was generally used on the XCB cores. Data measured at core voids and drilling breccia were rejected. Some discrete sample data are also presented, which were measured using a Molspin susceptibility unit at Sheffield University (Hounslow et al., this vol-

\footnotetext{
${ }^{1}$ Moore, J. C., Mascle, A., et al., 1990. Proc. ODP, Sci. Results, 110: College Station, TX (Ocean Drilling Program).

2 Department of Geology, University of Sheffield, Sheffield, S3 7HF, U.K

3 Present address: School of Environmental Sciences, University of East Anglia, Norwich, NR4 7TJ, U.K.
}

ume). All measurements are presented in SI volume susceptibility units, which are dimensionless.

The susceptibility values were assigned depths following the normal ODP procedure. However, as a result of more than $100 \%$ recovery in some cores there was sometimes a depth overlap of the data. In all cores except one (110-671B-41X) this overlap was minor, and not apparent in the depth-reduced data (Figs. 6 to 8). The data from Core 110-671B$41 \mathrm{X}$, which had $190 \%$ recovery, were compressed to fit the cored depth interval. Where core recovery is less than $100 \%$, as it frequently is in XCB cores, the data are drawn at the top of the cored interval, although this may not be the stratigraphically correct position.

\section{SEDIMENT SOURCES AND MAGNETIC SUSCEPTIBILITY}

There are essentially three types of magnetic behavior into which all minerals can be divided, ferromagnetic, paramagnetic, and diamagnetic (Thompson and Oldfield, 1986). Ferromagnetic minerals (e.g., titanomagnetites) have volume susceptibilities of the order of 5000 to $50000 \times 10^{-5}$ SI units and will tend to dominate the susceptibility if they occur in sufficient abundance. Paramagnetic minerals such as amphiboles, pyroxenes, chlorites, rhodochrosite, and other iron or manganese-bearing minerals have susceptibilities typically of 10 to $500 \times 10^{-5}$. Diamagnetic minerals such as calcite and quartz have small negative susceptibilities (e.g., 0.5 to $5 \times 10^{-5} \mathrm{SI}$ ).

The range of susceptibility values for the Pleistocene to Eocene sections enables a division of the stratigraphic sequence into two major units with distinctly different magnetic mineral contents (Fig. 2). These two susceptibility units are also reflected in the mineralogy of the coarse fractions (Y. Ogawa, pers. commun., 1986), suggesting that the Pleistocene to middle Miocene sediments are derived from the Lesser Antilles volcanic arc, while the lower Miocene to Eocene sediments are from the South American continent, in accord with other evidence. Volcanic ash, as both discrete air-fall layers and disseminated particles in the sediment, are present in the Pleistocene to Miocene sequence. Sigurdsson et al. (1980) estimate that $40 \%$ of the volcanic ash in the surface sediments is present as disseminated particles as opposed to discrete ash-fall layers. The similarity of the mean susceptibility throughout the Pleistocene and Pliocene indicates that the disseminated ash concentration is probably similar to surface sediment concentrations of 1 to $15 \%$ measured by Sigurdsson et al. (1980). This disseminated ash probably represents ash air-falls that are redistributed in the sediment by bioturbation. 


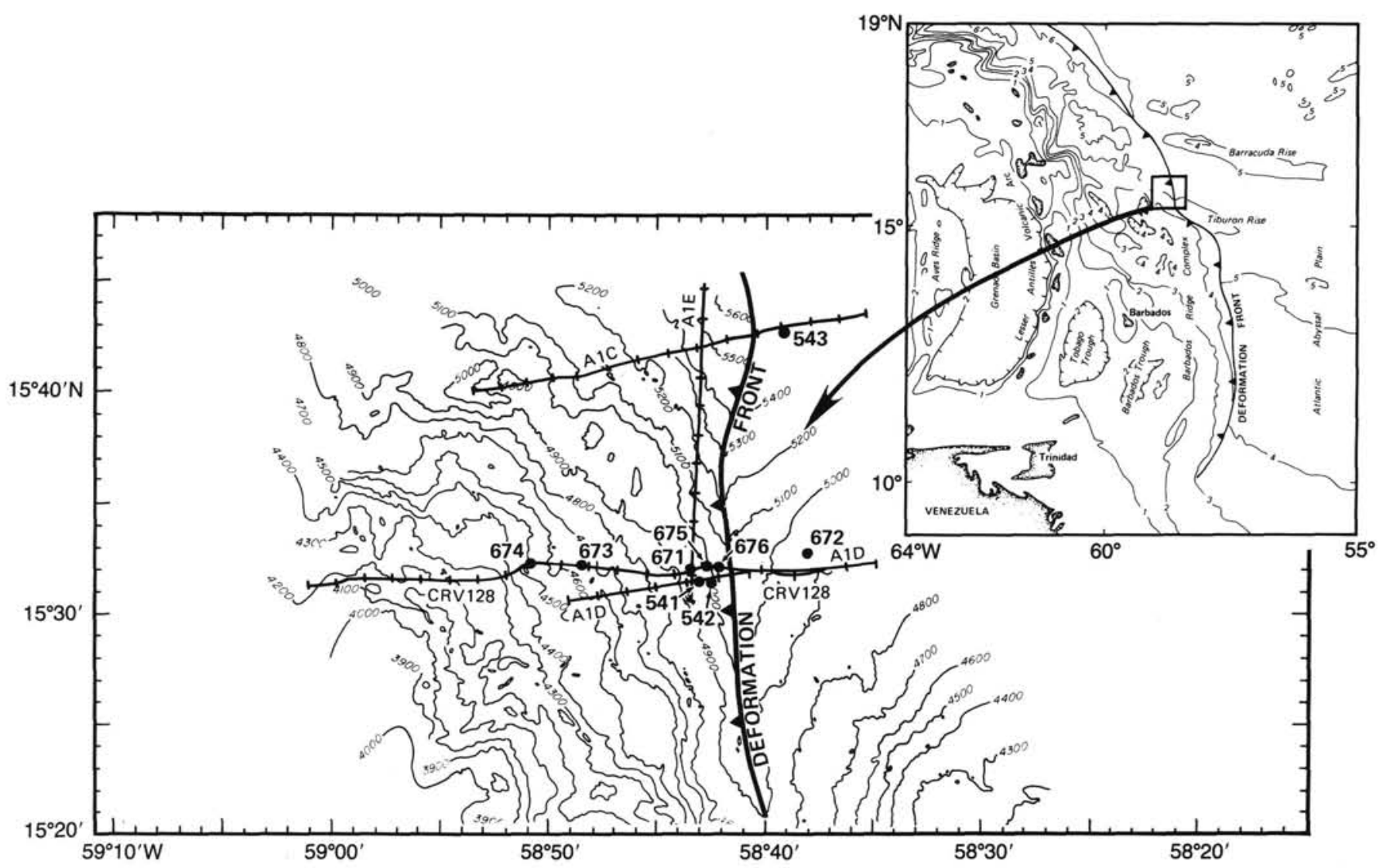

Figure 1. Location map for ODP Leg 110 and DSDP leg 78A sites, with inset showing Seabeam bathymetry.

Titanomagnetites generally dominate the remanence properties of most of the sediments (Hounslow et al., this volume). A parameter that is dependent to a large extent on the content of the ferromagnetic minerals is the natural remanent magnetization (NRM) intensity. This shows a good correlation with the susceptibility (Fig. 3), indicating that titanomagnetite is likely to be the mineral that dominates the susceptibility, particularly in the Pleistocene to middle Miocene part of the sequence. The good correlation of susceptibility and plagioclase content (Fig. 4 ), where the plagioclase is presumably reflecting the abundanceof ash, indicates that the titanomagnetite is largely derived from volcanic ash. Abundant titanomagnetites are seen in polished sections of ash layers, as both discrete particles and inclusions in other ash grains (Hounslow et al., this volume). In addition, the susceptibility strongly correlates with the occurrence of ash-rich layers (Fig. 5). However, this correlation is not a simple one, as not all ash layers are apparently rich in titanomagnetites. Black colored ashes and ash layers are generally rich in glass fragments and opaques and tend to dominate the ash succession, particularly in the Pleistocene and Pliocene, where they show a good correlation with high susceptibility values. Ash layers rich in lithic fragments do not necessarily correspond to peaks in susceptibility, but can correspond to lows. The latter relationship is common in the upper Miocene section where the prominent susceptibility lows correspond to weakly magnetic ashes (Figs. 2 and 8).

Diamagnetic material such as calcite, quartz, and water tend to lower the bulk sediment susceptibility by dilution because of their low susceptibility. This dilution phenomenon is strongly shown by calcite for both the major susceptibility units (Fig. 6). Notably, the dilution effect is not apparent for diamagnetic quartz, suggesting that the abundance of quartz may be partly related to that of more strongly magnetic minerals such as detrital paramagnetics.

The susceptibility record in the middle Miocene to Eocene sequence is thought to be derived from different mineral species than those in the ash-dominated unit above. Evidence of this is found in the anisotropy of magnetic susceptibility (Hounslow, this volume), which is dominantly carried by unknown paramagnetic minerals, when the sample susceptibility drops below about $90 \times 10^{-5}$ SI. In addition, the susceptibility is weakly dependent on the NRM intensity below a susceptibility value of about $60 \times 10^{-5} \mathrm{SI}$ in contrast to higher values, where there is a strong dependence (Fig. 3).

\section{STRATIGRAPHIC CORRELATION USING MAGNETIC SUSCEPTIBILITY}

The basic premise of stratigraphic correlation using susceptibility is that identical age sediments have identical magnetic mineral assemblages. The truth of this assumption, and how wide a geographic area to which it is applicable, depends upon whether there are processes that can laterally change these assemblages (Thompson and Oldfield, 1986).

\section{Perturbations to Susceptibility Correlation}

Differences in sedimentation rate and intensity of bioturbation will affect the depth-susceptibility signal. A slow sedimentation rate could result in two types of susceptibility response. A reduction of the background sedimentation rate in a sequence will result in a susceptibility increase, as a greater proportion of the sediment will be composed of ash. Condensation of the biostratigraphic zones by omission (i.e., erosion events) will proba- 


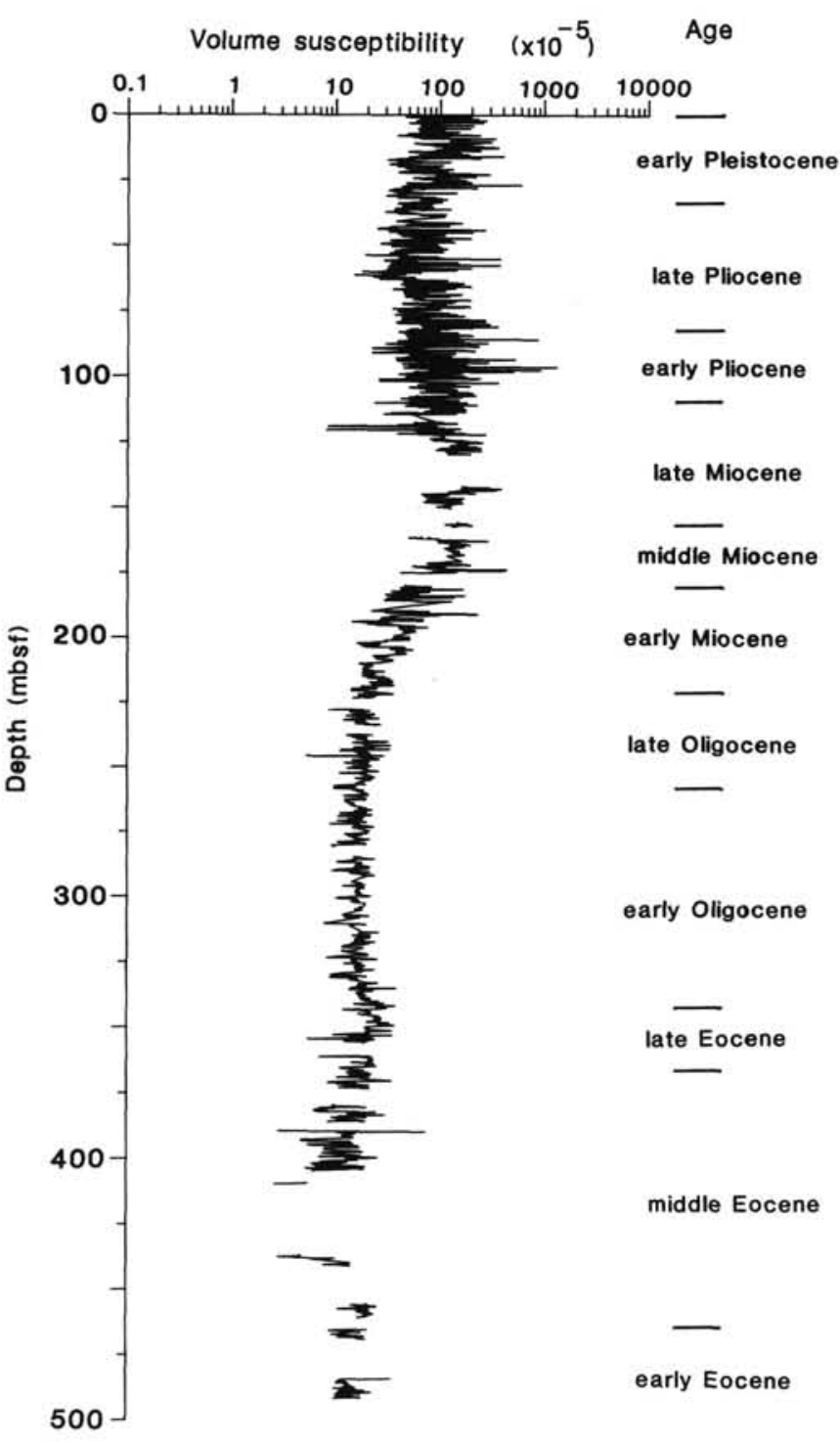

Figure 2. Whole-core volume magnetic susceptibility data (SI units) for Hole $672 \mathrm{~A}$ and biostratigraphic ages.

bly result in the same average susceptibility but a different susceptibility pattern with depth compared to a profile of continuous sedimentation. Bioturbation intensity will also profoundly influence the susceptibility record, tending to homogenize the abundance of magnetic minerals and leading to a record with broader and lower amplitude peaks. Sediment reworking or lateral transport will also disturb the susceptibility signal, leading to poor or non-correlation.

Steep bedding dips, common in Holes 671B and 676A, can lead to problems with correolation unless account is taken of this. Measurement interval and measurement positioning with respect to peak susceptibility values also influence the accuracy with which a continuous susceptibility porofile can be determined; it is unlikely that two identical continuous susceptibility sequences would be measured with exactly the same values. This problem is compounded if thin high-susceptibility, or low-susceptibility layers are present.

The extended core barrel (XCB) coring process is a major disturbing influence on the susceptibility record because it tends to mix up lithologies and lead to missing core, which is likely to occur at any place within the cored interval.

\section{Numbering Sequence and Correlation Rationale}

Hole $672 \mathrm{~A}$ was chosen as a reference susceptibility record on which prominent parts could be numbered. The sequence was arbitrarily divided up into an A-sequence in the Pleistocene and a B-sequence below this. The boundary between A- and B-sequences was chosen to be a prominent peak (BO) close to the biostratigraphic $C$. macintyrei Zone/CN12d boundary in Core $110-672 \mathrm{~A}-5 \mathrm{H}$. However, the $H$. sellii Zone (Clark, this volume) is missing in Hole $672 \mathrm{~A}$ so that the numbering in this zone is based on correlation with the record in Cores $110-676 \mathrm{~A}-5 \mathrm{H}$ to $-7 \mathrm{H}$.

The susceptibility correlations are first constrained by the biostratigraphic data that provide an initial correlation. The detailed correlation is then determined by the magnitude of the susceptibility and the depth variation, which should show a similar pattern. The correlation of the long continuous records covering at least two cores is fairly straightforward. The smaller the length of the susceptibility record, and the more disrupted this is, the greater the possibility of alternative interpretations. These are pointed out where relevant.

\section{PLEISTOCENE CORRELATIONS}

There is an excellent correlation of the Pleistocene sections from Hole 673A with Hole 672A (Fig. 5). The correlation of the records between holes and cores in terms of sub-bottom depth is shown in Table 1 and Figure 7.

\section{Holes 672A and 676A}

The sequence in Hole $672 \mathrm{~A}$ has one repeated section, which corresponds almost exactly to Core $110-672 \mathrm{~A}-4 \mathrm{H}$. The susceptibility record in this core is expanded comapared to its equivalent in Core $110-672 \mathrm{~A}-3 \mathrm{H}$, indicating a steeper bedding dip. This part of the core is probably bounded by faults accounting for the absensce of the $H$. Sellii Zone in this hole. The frontal thrust fault in Hole $676 \mathrm{~A}$ is placed at 30.5 - to $31.5 \mathrm{mbsf}$, with the sequence A1-A28 located above the fault, and A9-A33 below. There is a small expanded interval of $1.5 \mathrm{~m}$ in about the middle of Core $110-676 \mathrm{~A}-5 \mathrm{H}$, which may represent a splay off the main thrust fault.

\section{Hole 671B}

The susceptibility record in the upper-most of the Pleistocene records of Hole $671 \mathrm{~B}$ is generally more condensed than that in Holes $672 \mathrm{~A}$ or $676 \mathrm{~A}$. The A1 to A9 sequence is complete in Cores 110-671B-1H and the top of 110-671B-2H, but below this depth to the top of Core 110-671B-4H there is not a simple correlation with Holes $672 \mathrm{~A}$ or $676 \mathrm{~A}$. Peaks A22 to A26 are present in Cores $110-671 \mathrm{~B}-3 \mathrm{H}$, but at $25 \mathrm{mbsf}$ the standard sequence is broken and does not clearly resume until A28 in Core $110-671 \mathrm{~B}-4 \mathrm{H}$. There may be a minor fault or faults between these two positions ( 25 to $29 \mathrm{mbsf}$ ). The low value at the very base of Core 110-671B-3H is somewhat suggestive of A25, although being at core boundaries makes correlation difficult. The sequence below A9 in Core 110-671B-2H and above A22 in Core 110-671B-3H does not clearly match any others. The relatively high susceptibility in the two broad peaks between the middle and bottom of Core 110-671B-2H is suggestive of a condensed ash-sediment record, because the bedding dips are near zero. The simplest interpretation, without invoking extensive dismembering faults is shown in Figure 5. However, it is equally possible that the two broad peaks in Core 110-671B-2H may be condensed peaks A10 to A15, which would make it necessary to place a fault at the top of Core 110-671B-3H. The unnumbered sequence in Core 110-671B-2H (Fig. 5) may be a repitition of A6 to A8, but it does not clearly match those peaks in Holes $676 \mathrm{~A}$ or $672 \mathrm{~A}$. The nannofossil data (Clark, this volume) also suggests some stratigraphic repetition at this level. Any interpre- 


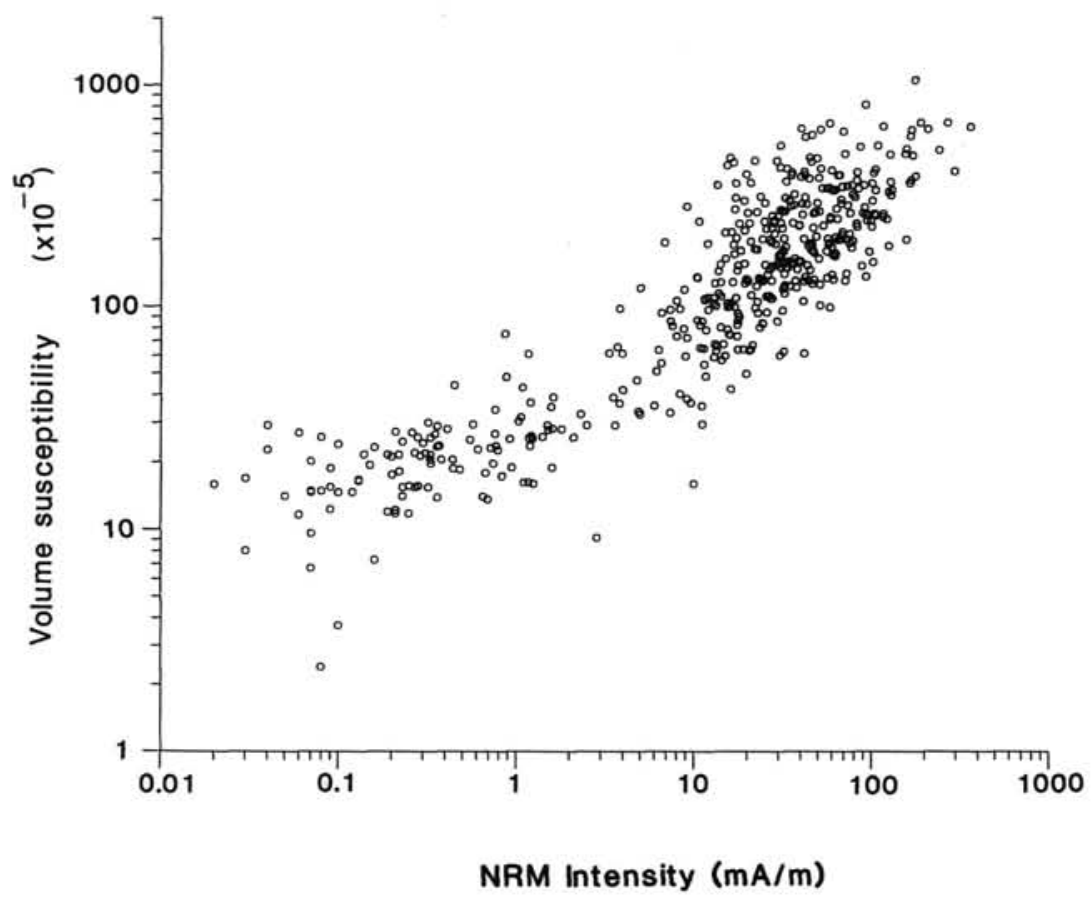

Figure 3. Volume magnetic susceptibility vs. NRM intensity for discrete sample data.

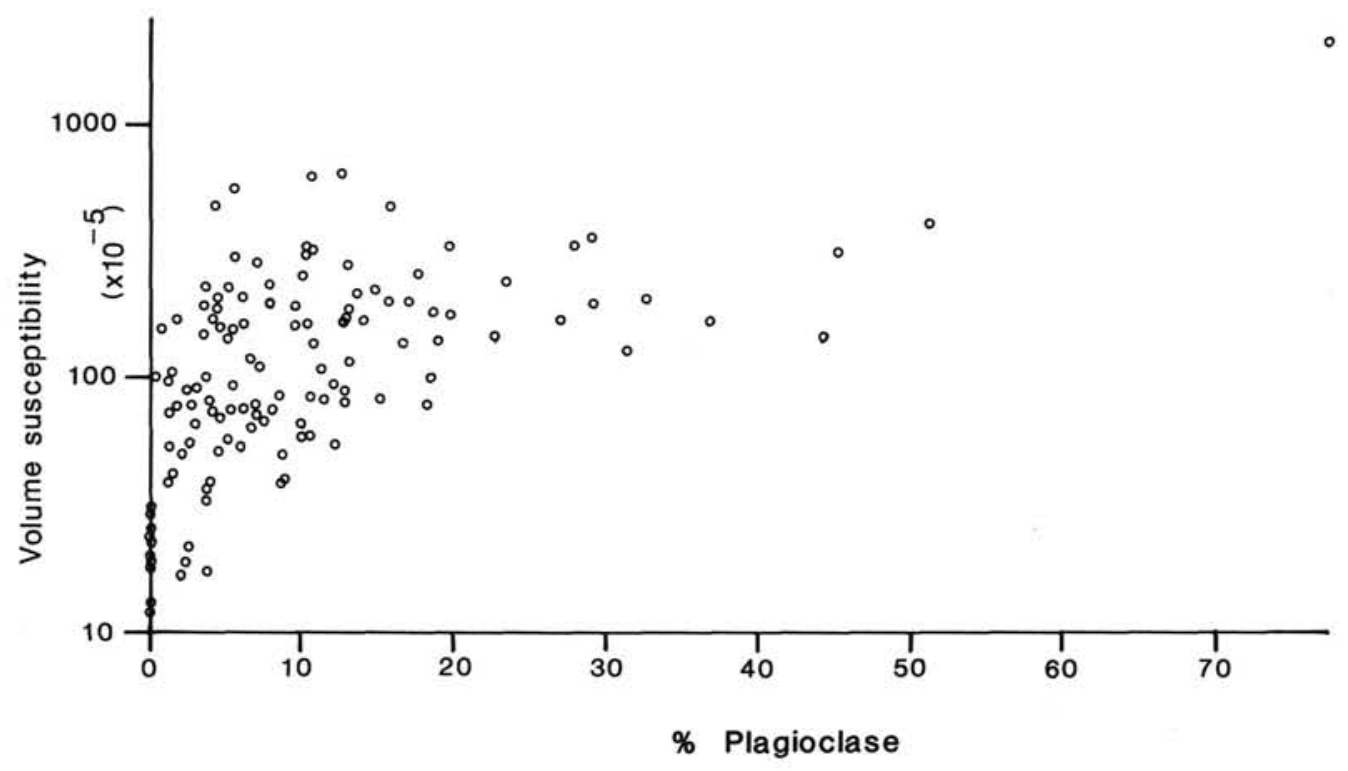

Figure 4. Whole-core volume magnetic susceptibility vs. the plagioclase content determined by XRD (Mascle, Moore, et al., 1988). The stratigraphic coincidence of these data sets is within $10 \mathrm{~cm}$.

tation requires either at least three to four faults in the top $30 \mathrm{~m}$, or a sedimentation history quite different to that at the other sites.

The other Pleistocene sequence in Hole 671B is from the $\mathrm{XCB}$-cored part of the hole (Fig. 5). This section starts at the bottom of Core 110-671B-14X, where Miocene rests upon the $P$. lacunosa Zone. Core 110-671B-15X contains sub-vertical bedding dips, with subhorizontal dips in Cores 110-671B-17X to $-22 \mathrm{X}$. The generally high susceptibility recorded in Cores 110 671B-15X and -17X may be correlated with the peaks A10 to A15 (or A18), and the somewhat lower susceptibilities in Core 110-671B-18X may correspond to the broad low A19 to A21 low. However, the shallow bedding dips in Core 110-671B-17X are incompatible with the susceptibility record, unless this part of the sequence is extensively dismembered by faults. Core 110671B-20X may correspond to A30 to B0, which is compatible with the nannofossil data. However, the thick $C$. macintyrei Zone in Cores 110-671B-20X to $-22 \mathrm{X}$ is suggestive of a fault somewhere in Core 110-671B-21X, given the shallow bedding dips in this interval. There is evidence for this in low-angle faults found in this core. Core 110-671B-22X appears to correlate with A25 to A31, with A29 missing (fault at 201.7 mbsf; Mascle, Moore, et al., 1988), but this correlation is at variance with the nannofossil data (Clark, this volume). 


\section{Hole 673B}

The susceptibility record in Hole 673B is complicated because of the debris flow in Cores 110-673B-1H to -2H (Mascle, Moore, et al., 1988). The A1 to A15 sequence correlates across the debris flow with the A7 peak present on both sides of this unit (although this peak is larger than in the other holes). This would suggest that the debris flow represents one depositional event. The best-fitting interpretation for Cores $110-673 \mathrm{~B}-3 \mathrm{H}$ to $-4 \mathrm{H}$ is suggested by two faults, one in the lower half of Core $110-671 \mathrm{~B}-3 \mathrm{H}$ with the A16-A23 peaks missing, and one in the top half of Core 110-673B-4H with the A29 peak faulted out. This interpretation is supported by evidence of extensive faulting in these parts of the cores. The sequence of peaks A30 to B3 can be traced up to the lithologic, and presumably stratigraphic, boundary in Core 110-673B-5H (Mascle, Moore, et al., 1988). However, a CN12a nannofossil zonation within $50 \mathrm{~cm}$ of this boundary (Clark, this volume) may indicate that the suggested correlation for the top of Core 110-673B-5H, close to the boundary, may be somewhat fortuitous.

\section{PLIOCENE AND MIOCENE CORRELATIONS}

For piston-cored sections (Cores $110-672 \mathrm{~A}-1 \mathrm{H}$ to $-14 \mathrm{H}, 110$ $676 \mathrm{~A}-1 \mathrm{H}$ to $-11 \mathrm{H}, 110-671 \mathrm{~B}-1 \mathrm{H}$ to $-10 \mathrm{H})$ the correlation between holes is very clear down to about B45 (Fig. 8 and Table 2). Below this peak the susceptibility record in Hole 672A appears to be expanded compared to that of Holes 671B and 676A. The peaks labeled B42 to B45 in Hole 672A are not fully represented in Hole 671B but are replaced by only three peaks, and the record for Hole 676A is incomplete. A fault is noted in Section $110-672 \mathrm{~A}-10 \mathrm{H}-6$, suggesting that there may be a repetition of a single peak, B42/B43. However, faults are also noted in Core $110-671 \mathrm{~B}-9 \mathrm{H}$ at the same position, perhaps indicating the absence of B44 from the record. Peaks B53 to B57 in Hole 672A are represented by a different series of peaks in Hole 671B. There is evidence of faulting in both holes at the position of these peaks, suggesting that perhaps neither susceptibility sequence may be a true undisplaced record. These range of peaks have not been measured in another hole, so it is not possible to define a unique pattern of peaks over this range. An additional peak is also present between B60 and B61 in Hole 110-671B-11H. The proximity of these complications to the major thrust in Core 110-671B-13X, may indicate that low-angle faults could be responsible for these problems in Hole 671B. Alternatively, the poor correlation could be a precursor to the significantly different susceptibility records between holes in the Miocene.

There is clear evidence in the core and the susceptibility record of a minor fault in Core $110-676 \mathrm{~A}-10 \mathrm{H}$ that repeats B15 to $\mathrm{B} 19$. The length of the cored interval in Core $110-676 \mathrm{~A}-12 \mathrm{H}$ is too short to fit the peaks B32-B39, suggesting that a fault is present toward the top of this core, cutting out about $5.5 \mathrm{~m}$. Also, the length of the record B43-B49 in Core 110-676A-13X indicates that the bedding in this core is dipping much more steeply than in Core $110-676 \mathrm{~A}-11 \mathrm{H}$.

\section{The Miocene Sequence}

Below B64 the character of the susceptibility record changes. There are no prominent peaks, but instead the susceptibility is more random, with lows being the main markers. The sequence in Hole $672 \mathrm{~A}$ is also considerably expanded in parts compared to Holes 671B and 676A, and the degree of similarity in the record is much less (Fig. 9). This dissimilarity could be a result of more lateral reworking or extensive diagenetic dissolution of the titanomagnetites.

The prominent lows (e.g., B65, B66, B67, and B68) all correspond to ash layers, which evidently have a very low titanomagnetite content (Fig. 9). This part of the record (approximately below $\mathrm{CN} 10 \mathrm{c}$ to $\mathrm{CN} 9 \mathrm{~b}$ ) would appear to mark a change in the type of volcanism, from one in which the ashes are predominantly rich in titanomagnetite to one in which there was little ash titanomagnetite. However, the sediment source giving rise to the background sedimentation was sufficiently rich in titanomagnetite to keep the overall susceptibility the same. Nevertheless, there are ash layers rich in magnetite such as those corresponding to B70, B71, and B72 (Fig. 9). These highly magnetic ash layers seem to dominate the susceptibility record again in the middle Miocene sequence in Hole 672A (Cores 110-672A$21 \mathrm{X}$ and $-22 \mathrm{X}$ ). The early Miocene was a time at which there was a steady reduction in the amount of titanomagnetite in the background sedimentation.

The steadily increasing susceptibility in Cores 110-671B-50X to $-54 \mathrm{X}$ is not matched in Hole $672 \mathrm{~A}$. The increased average susceptibility over this range in Hole 671B may be a result of the lower porosity but seems to be too large to be accounted for entirely by this. Alternative explanations may be a larger abundance of disseminated ash, or perhaps the precipitation of other magnetic minerals such as iron and manganese oxides just above the décollement horizon.

\section{CONCLUSIONS}

The high degree of dependence of the magnetic susceptibility upon the volcanic ash content is largely responsible for the high degree of correlation attained with this simple technique. However, an examination of Figures 5, 8, and 9 shows that the visibly determined ash content and ash layers show a poor degree of correlation between holes. For example, the sequence from B8 to B10 shows either three to four ash layers, which are not readily correlated, even though the susceptibility shows a good degree of correlation. Reasons for this could be differences in the degree of bioturbation between depositional sites or perhaps minor current reworking and entrainment of the air-fall ashes into shallow (i.e., less than $5 \mathrm{~cm}$ deep) depositional hollows, with little deposition over surface hummocks (Sigurdsson et al., 1980). The continuous nature of the susceptibility record, reflecting small differences in the abundance of titanomagnetites, makes it a better tool for correlation than the visual recognition of discrete ash layers.

A suggested correlation of the susceptibility stratigraphy with the nannofossil zonal boundaries (Clark, this volume) is shown in Figure $7 \mathrm{~b}$. The nannofossil zones show a consistent relationship with the susceptibility record in each hole, with the zonal boundaries being within a range of about one peak of the suggested correlation shown in Figure $7 \mathrm{~b}$. The exception to this is the $H$. sellii/C. macintyrei boundary that shows less consistent relationships between holes (Fig. 5). The uncertainty in these correlations is probably due to the frequently faulted nature of this boundary.

The summary of the susceptibility correlations between holes and the position of faults with the relevant amount of throw is shown in Figure $7 \mathrm{a}$. The faults with throws of $120 \mathrm{~m}$ in Hole $671 \mathrm{~B}$ and $22 \mathrm{~m}$ in Hole $676 \mathrm{~A}$ correspond to the major thrust faults. The reverse fault at 190 mbsf in Hole $671 \mathrm{~B}$ may be a secondary low-angle fault associated with the major thrust at 128 mbsf.

Other faults of both reverse and normal displacement are present in the holes examined. Of particular significance are the two faults identified in Hole 672A. These are not likely to be associated with the deformation of the prism toe, but rather a consequence of differential sediment compaction. Williams (1987) has identified faults in Madeira Abyssal Plain sediments that are localized near basement highs and have both reverse and normal geometries, with throws of up to $25 \mathrm{~m}$. He has suggested that these faults result by differential dewatering associated with localized overpressuring. The most plausible explanation for these faults identified in Hole 672A, and perhaps other 

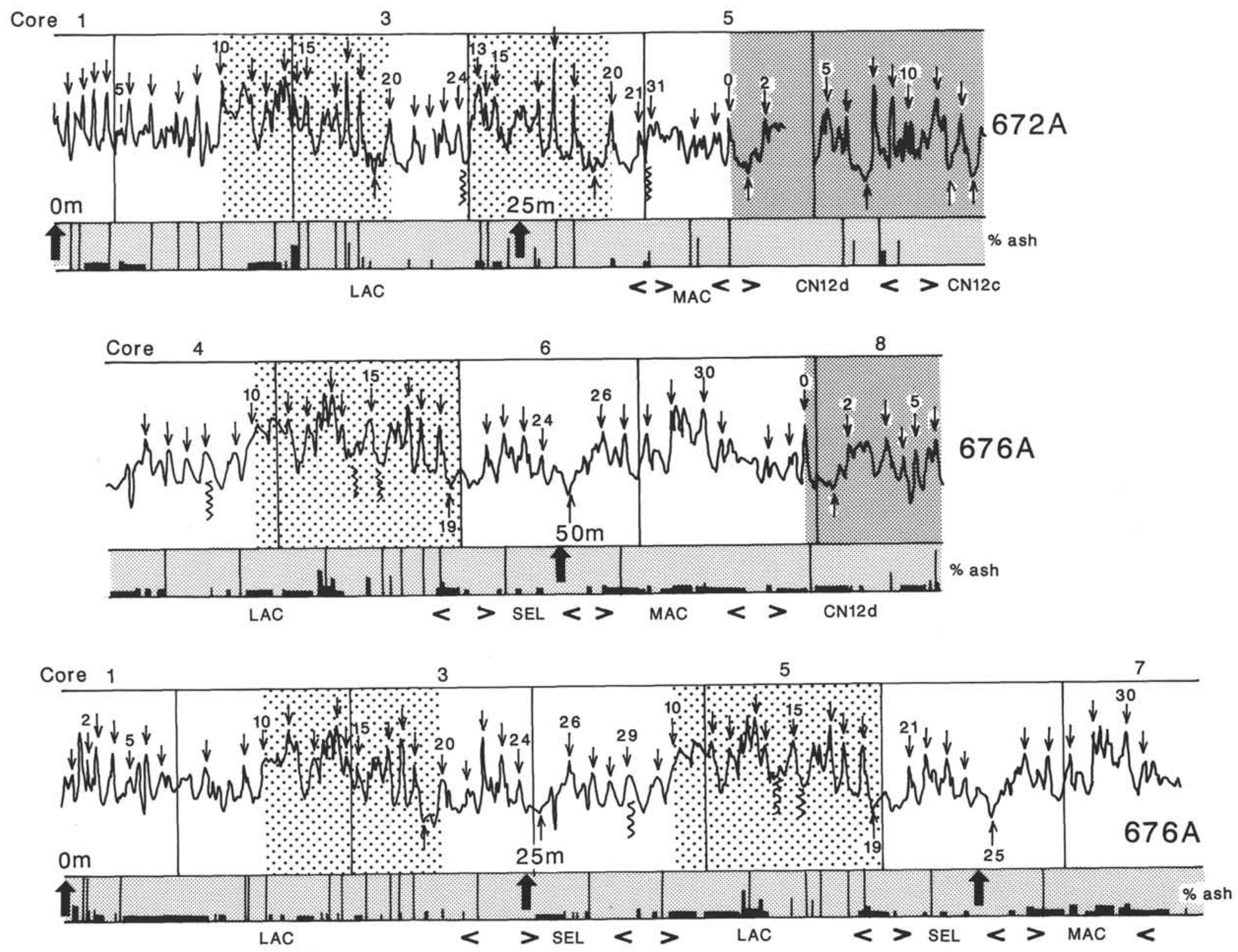

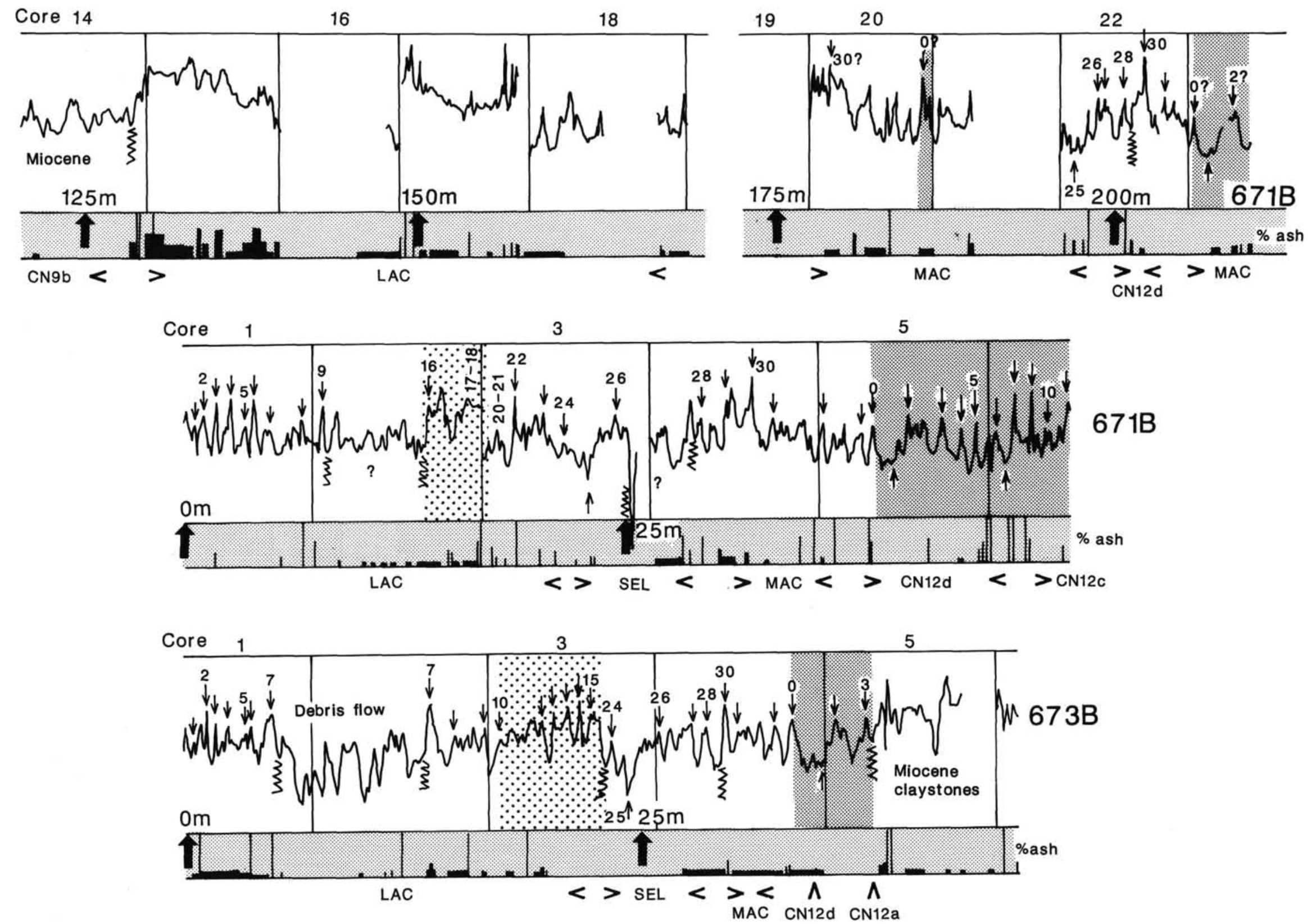

Figure 5. Whole-core susceptibility data for the Pleistocene sections. The data is drawn on a logarithmic scale between two horizontal lines representing the $1 \times 10^{-5}$ and $1000 \times 10^{-5}$ (SI) susceptibility values. Also shown are the ash content values in the rows of light shading. A full vertical line represents a discrete ash layer (Mascle, Moore, et al., 1988). The core numbers and depth scales (mbsf, marked with large arrow) are indicated for each hole. A numbered part of the susceptibility record is indicated by a small vertical arrow. These peaks and troughs are numbered sequentially down the holes. A break in the susceptibility record, or other biostratigraphic or lithostratigraphic breaks, are indicated by a vertical wiggly line. That part of the record belonging to the B-sequence of peaks is marked with medium shading. The correlation of the group of peaks A10-A20 between the holes is indicated with heavy stipple. The nannofossil zonation determinations of Clark (this volume) are also indicated, where LAC $=$ P. lacunosa Zone, SEL $=H$. sellii Zone; MAC $=$ C. macintyrei Zone. 


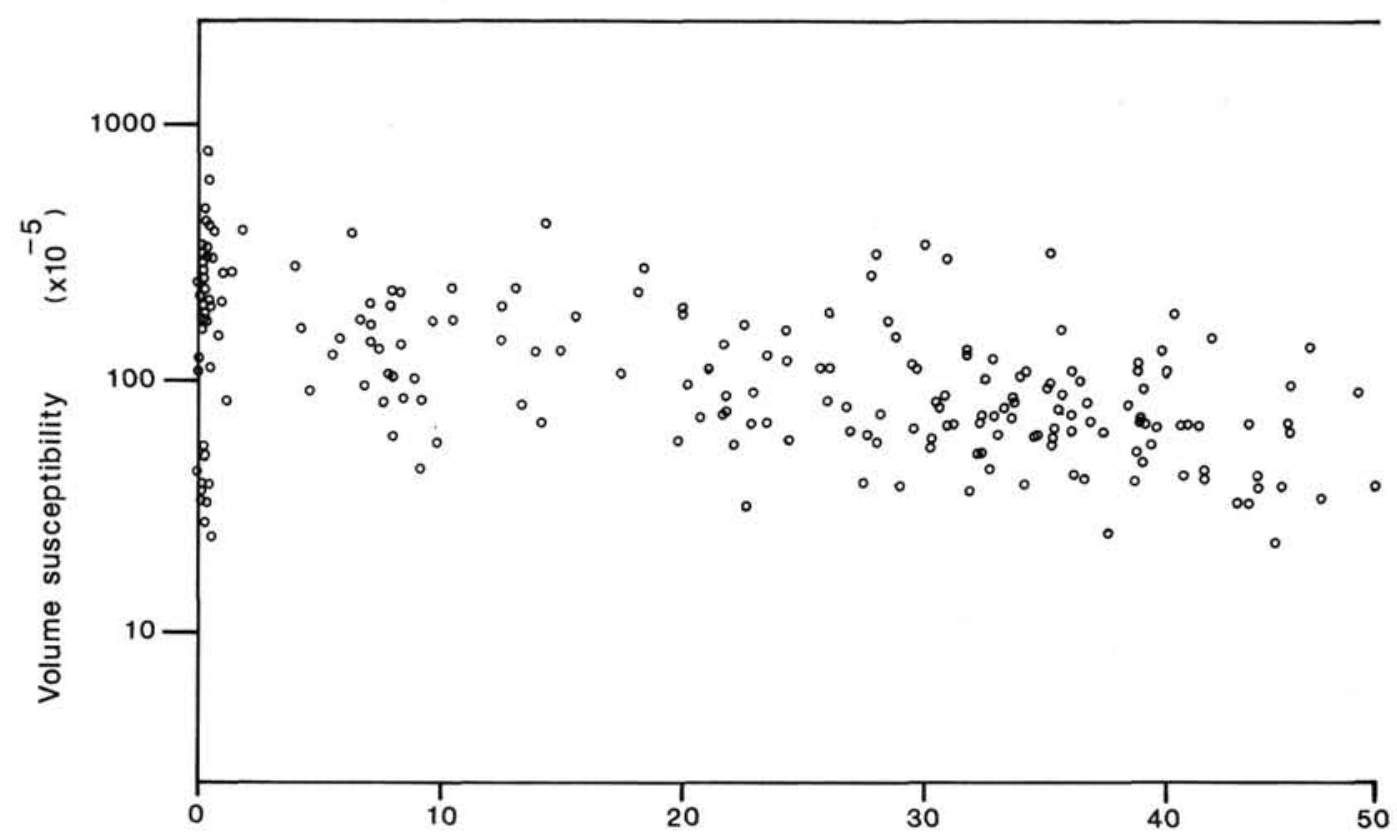

A

Carbonate Content (\%)

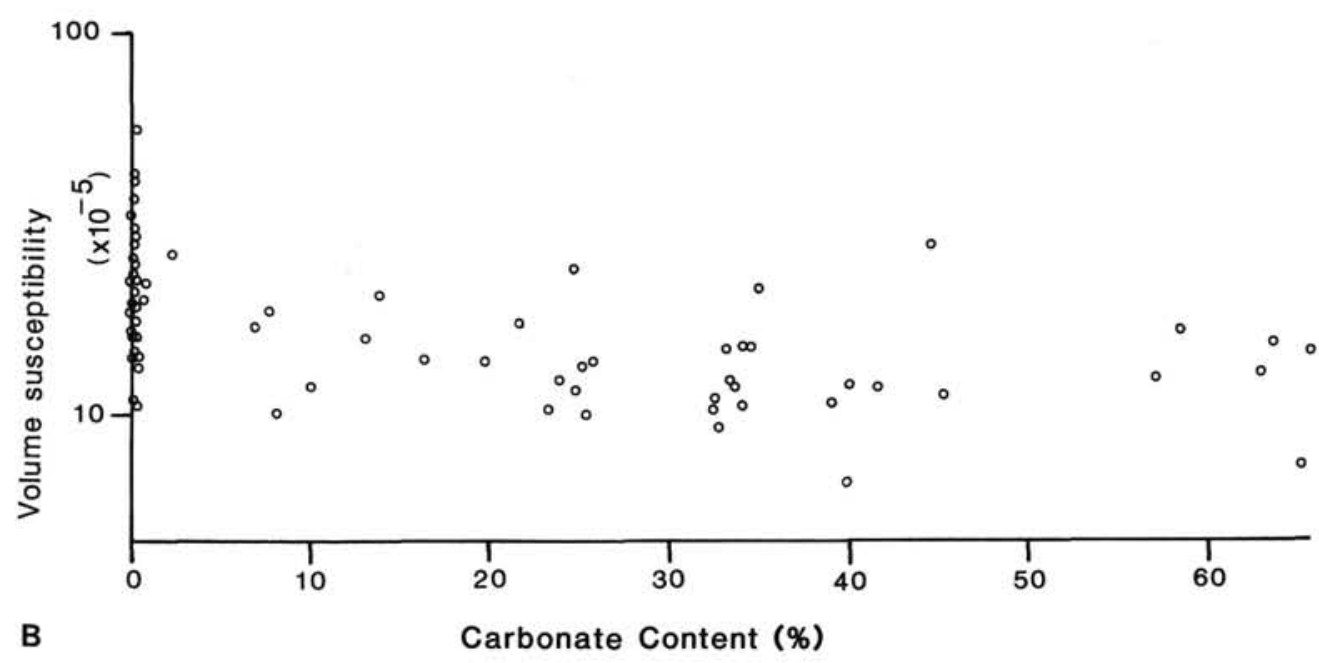

Figure 6. Whole-core volume susceptibility vs. carbonate content determined by coulometric analysis (Mascle, Moore, et al., 1988) for (A) Pleistocene, Pliocene, and upper Miocene for Holes 671B and 672A; (B) middle Miocene to Eocene for Holes $671 \mathrm{~B}$ and $672 \mathrm{~A}$. The stratigraphic coincidence of these data sets is within $10 \mathrm{~cm}$.

minor faults at Sites 671 and 676 is that they result by similar processes as suggested for the abyssal plain sediments examined by Williams (1987).

\section{ACKNOWLEDGMENTS}

The shipboard measurements could not have been undertaken without the help of John Tauxe, Jerri Wackler, and Kevin Rodgers. Peter Vrolijk kindly provided the ash content record. Yujiro Ogawa is thanked for his stimulating discussions.

\section{REFERENCES}

Hilton, J., 1987. A simple model for the interpretation of magnetic records in lacustrine and oceanic sediments. Quat. Res., 27:160-166.

King, J., Banerjee, S. K., Marvin J., and Ozdemir, O., 1982. A comparison of different magnetic methods for determining the relative grain size of magnetite in natural materials: some results from lake sediments. Earth. Planet. Sci. Lett., 59:404-419.

Mascle, A., Moore J. C., et al., 1988. Proc. ODP, Init. Repts., 110: College Station, TX (Ocean Drilling Program).
Robinson, S. G., 1982. The late Pleistocene paleoclimatic record of North Atlantic deep-sea sediments revealed by mineral-magnetic measurements. Phys. Earth. Planet. Int., 42:22-47.

Sigurdsson, H., Sparks, R.S.J., Carey, S. N., and Huang, T. C., 1980. Volcanogenic sedimentation in the Lesser Antilles. J. Geol., 88:523540.

Thompson, R., Bloemendal, J., Dearing, J. A., Oldfield, F., Rummery, T. A., Stober, J. C., and Turner, G. M., 1980. Environmental applications of magnetic measurements. Science, 207:481-486.

Thompson, R., and Oldfield, F., 1986. Environmental Magnetism: London (Allen and Unwin).

Williams, S.R.J., 1987. Faulting in abyssal plain sediments, Great Meteor East, Madeira Abyssal Plain. In Weaver, P.P.E., and Thompson, J. (Eds.), Geology and Geochemistry of Abyssal Plains: Spec. Publ., Geol. Soc. London, 31:87-104.

Date of initial receipt: 2 December 1987

Date of acceptance: 14 February 1989

Ms 110B-159 
Table 1. Depth correlations for the Pleistocene (susceptibility sequence A). Depths are in mbsf.

\begin{tabular}{|c|c|c|c|c|}
\hline $\begin{array}{c}\text { Sus. } \\
\text { peak no. }\end{array}$ & $\begin{array}{l}\text { Hole } \\
671 B\end{array}$ & $\begin{array}{l}\text { Hole } \\
676 \mathrm{~A}\end{array}$ & $\begin{array}{l}\text { Hole } \\
672 \mathrm{~A}\end{array}$ & $\begin{array}{l}\text { Hole } \\
673 B\end{array}$ \\
\hline 1 & 0.7 & 0.6 & 0.8 & 0.7 \\
\hline 2 & 1.2 & 1.5 & 1.5 & 1.5 \\
\hline 3 & 1.9 & 2.0 & 2.3 & 1.9 \\
\hline 4 & 2.7 & 2.9 & 2.9 & 2.5 \\
\hline 5 & 3.5 & 3.9 & 3.8 & 3.5 \\
\hline 6 & 4.0 & 4.7 & 4.1 & 4.0 \\
\hline 7 & 5.1 & 6.0 & 5.3 & $5.2,14.0$ \\
\hline 8 & 6.8 & 8.0 & 6.7 & 15.4 \\
\hline 9 & 7.9 & $10.0,32.1$ & 7.8 & 17.0 \\
\hline 10 & & $11.1,33.2$ & 9.2 & 18.0 \\
\hline 11 & & $12.3,35.0$ & 10.4 & 20.3 \\
\hline 12 & & $13.6,36.1$ & 11.5 & 21.0 \\
\hline 13 & & $14.9,37.3$ & $12.6,22.9$ & 21.7 \\
\hline 14 & & $15.3,37.9$ & $13.0,23.2$ & 22.4 \\
\hline 15 & & $16.0,39.5$ & $13.7,23.8$ & 23.0 \\
\hline 16 & 14.2 & $17.7,41.4$ & $15.5,26.0$ & \\
\hline 17 & $15.1-16.5$ & $18.4,43.1$ & $15.9,27.0$ & \\
\hline 18 & & $18.9,43.1$ & $16.6,28.0$ & \\
\hline 19 & & $19.3,43.7$ & $17.3,29.1$ & \\
\hline 20 & $17.2-18.0$ & 20.4 & $18.1,29.9$ & \\
\hline 21 & & $21.8,45.5$ & $19.4,31.4$ & \\
\hline 22 & 18.8 & $22.7,46.5$ & 20.1 & \\
\hline 23 & 20.4 & $23.7,47.4$ & 21.0 & \\
\hline 24 & 21.6 & $24.7,48.3$ & 21.8 & 24.2 \\
\hline 25 & $22.3,197.0$ & $25.8,50.0$ & & 25.1 \\
\hline 26 & $24.6,198.9$ & $27.3,51.8$ & & 26.8 \\
\hline 27 & 199.3 & $28.7,53.0$ & & 27.9 \\
\hline 28 & $29.3,201.0$ & $29.6,54.2$ & & 29.5 \\
\hline 29 & 30.5 & $30.6 ? 55.6$ & & \\
\hline 30 & $31.8,179.0,202.3$ & 57.2 & & 30.5 \\
\hline 31 & $33.0,179.0,202.3$ & 58.2 & 32.0 & 31.2 \\
\hline 32 & $36.0,183.0$ & 60.6 & 34.4 & 33.3 \\
\hline 33 & $38.3,184.7$ & 62.0 & 35.4 & \\
\hline BO & $39.0,185.8,206.0 ?$ & 62.6 & 36.2 & 34.4 \\
\hline
\end{tabular}


$673 \mathrm{~A}$

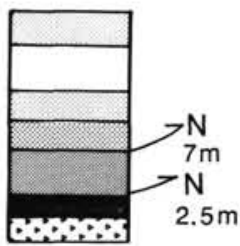

A
671B
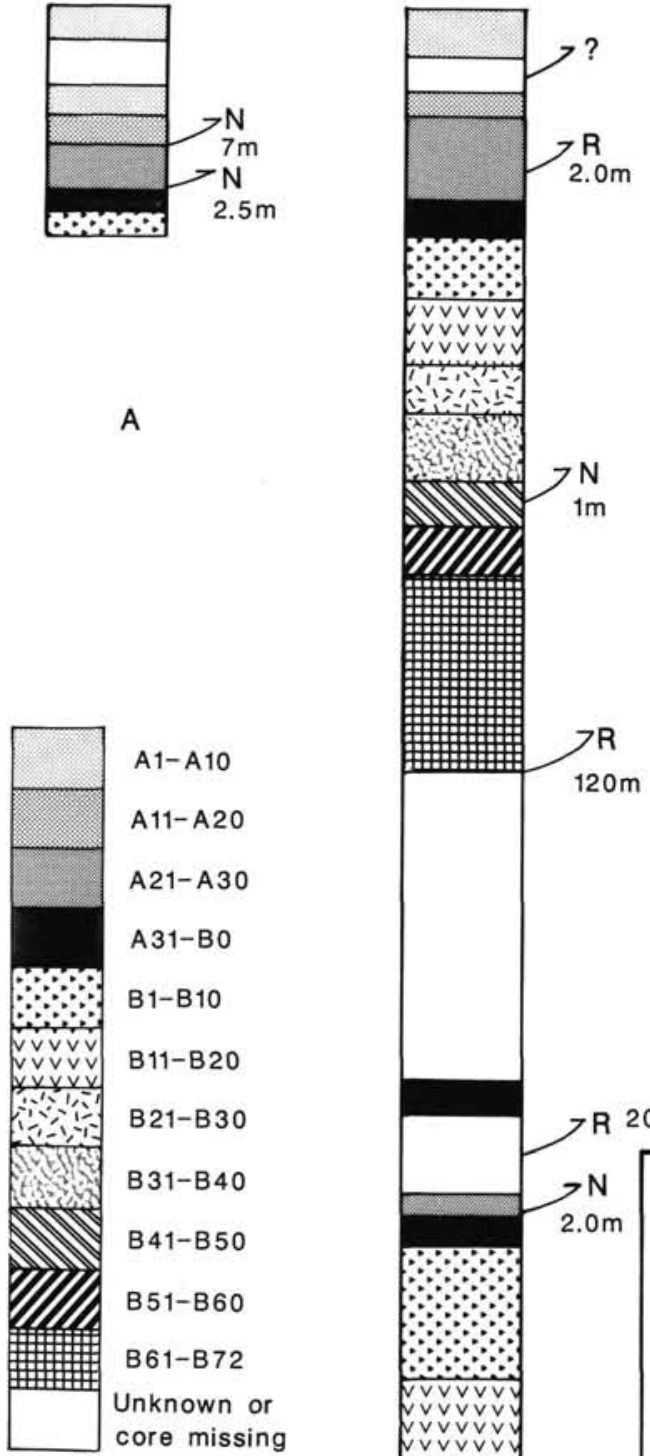

A1- A10

$\mathrm{A} 11-\mathrm{A} 20$

A21-A30

A 31-Bo

$B 1-B 10$

B11-B20

B21-B30

B31-B40

B 41-B50

B51-B60

B61-B72

Unknown or core missing

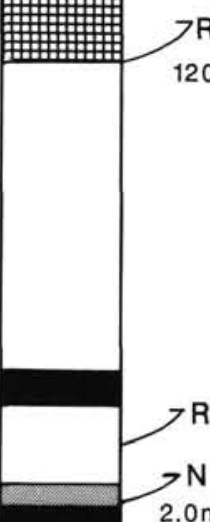

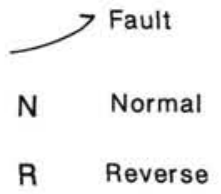

$676 \mathrm{~A}$
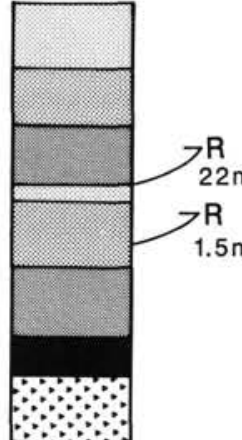

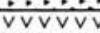

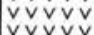

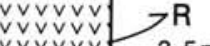

$3.5 \mathrm{~m}$

$\therefore=-7=11$
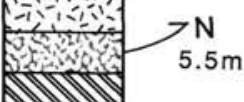

$5.5 \mathrm{~m}$
$672 \mathrm{~A}$

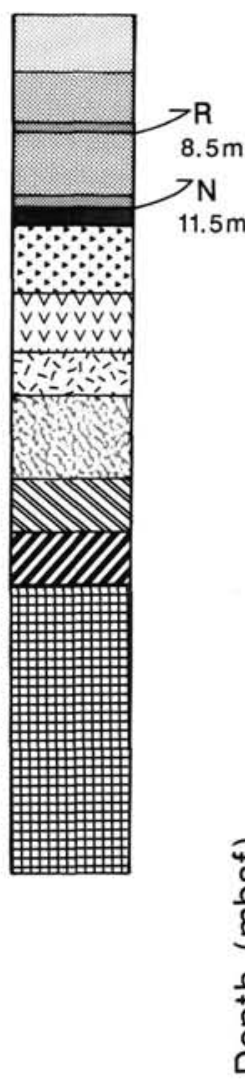

$-50$

$-100$

$-150$

\begin{tabular}{|c|c|}
\hline Zonal Boundaries & Peak No. \\
\hline P.lacunosa/H.sellii & A24 \\
\hline H.sellii/C.macintyrei & A28 \\
\hline C.macintyrei/CN12d & BO \\
\hline $\mathrm{CN} 12 \mathrm{~d} / \mathrm{CN} 12 \mathrm{C}$ & B9 \\
\hline $\mathrm{CN} 12 \mathrm{c} / \mathrm{CN} 12 \mathrm{~b}$ & B14 \\
\hline $\mathrm{CN} 12 \mathrm{~b} / \mathrm{CN} 12 \mathrm{a}$ & B18 \\
\hline CN12a/CN11b & B47 \\
\hline CN11b/CN11a & B55 \\
\hline CN11a/CN10C & B64/B65 \\
\hline $\mathrm{CN} 10 \mathrm{c} / \mathrm{CN} 10 \mathrm{~b}$ & B64/B65 \\
\hline $\mathrm{CN} 10 \mathrm{~b} / \mathrm{CN} 10 \mathrm{a}$ & B65/B66 \\
\hline $\mathrm{CN} 10 \mathrm{a} / \mathrm{CN} 9 \mathrm{~b}$ & B65/B66 \\
\hline \multicolumn{2}{|c|}{ B } \\
\hline
\end{tabular}

Figure 7. (A) summary of susceptibility correlations between Sites 673,671, 676, and 672, based on groups of susceptibility peaks. The position of faults, their sense of displacement and amount of throw are indicated. (B) Suggested correlation of the nannofossil zonal boundaries to the susceptibility peak numbers. A / indicates that the zonal boundary falls between the numbered peaks. 

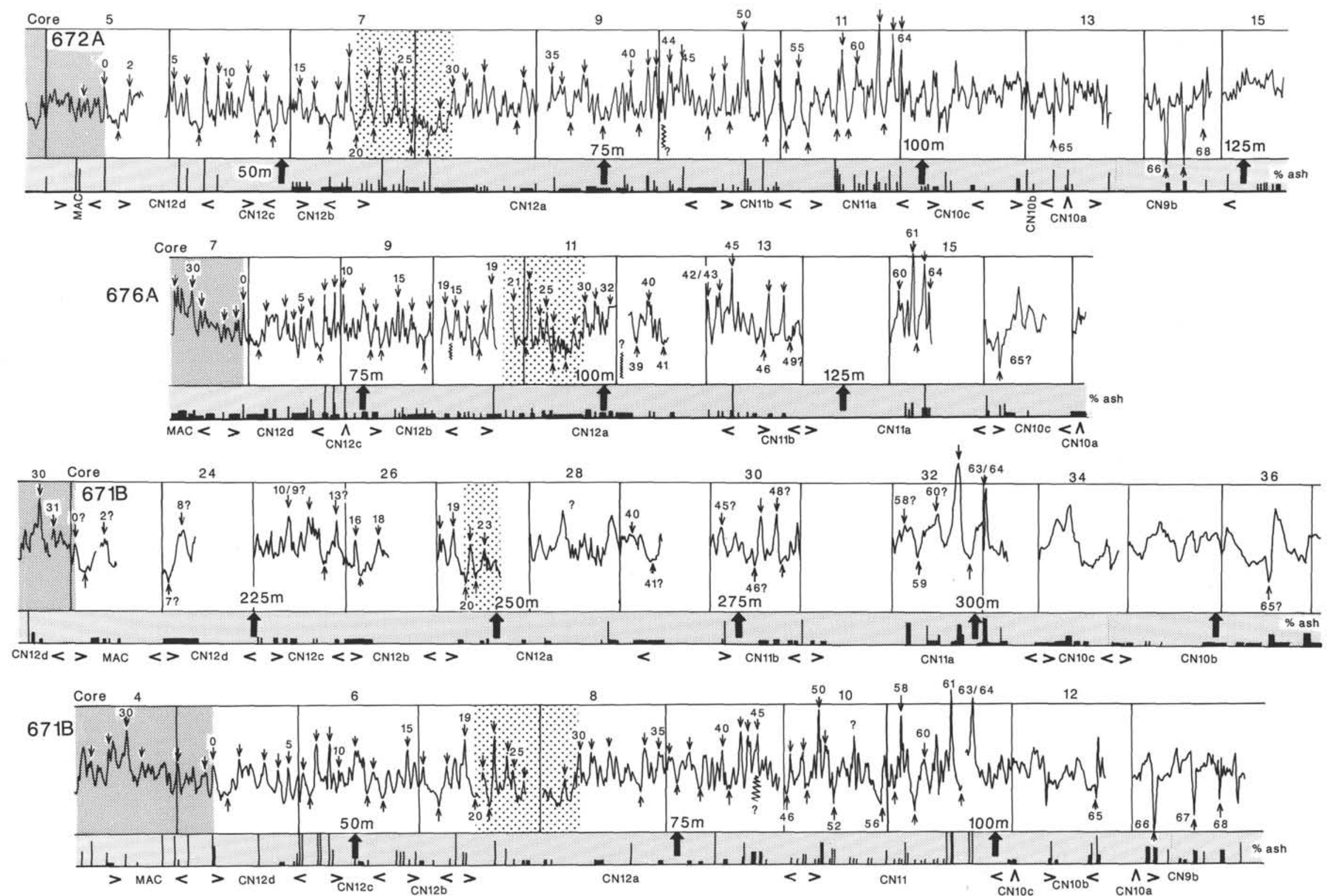

Figure 8. Whole-core magnetic susceptibility data for the Pliocene sections. The A-sequence of the susceptibility record is marked by medium shading, and the correlation of the group of peaks 
Table 2. Depth correlations for the Pliocene and Miocene (susceptibility sequence B). Depths are in mbsf.

\begin{tabular}{|c|c|c|c|c|}
\hline $\begin{array}{c}\text { Sus. } \\
\text { peak no. }\end{array}$ & $\begin{array}{l}\text { Hole } \\
671 B\end{array}$ & $\begin{array}{l}\text { Hole } \\
676 \mathrm{~A}\end{array}$ & $\begin{array}{l}\text { Hole } \\
672 \mathrm{~A}\end{array}$ & $\begin{array}{l}\text { Hole } \\
\text { 673B }\end{array}$ \\
\hline 1 & $40.0,207.7 ?$ & 64.1 & 37.3 & 36.2 \\
\hline 2 & $40.8,209.0 ?$ & 65.0 & 38.2 & 37.0 \\
\hline 3 & 42.7 & 67.0 & & $38.7 ?$ \\
\hline 4 & 43.7 & 67.9 & & \\
\hline 5 & 44.4 & 68.6 & 41.7 & \\
\hline 6 & 45.9 & 69.6 & 42.6 & \\
\hline 7 & $46.3,215.6 ?$ & 70.6 & 43.7 & \\
\hline 8 & $46.8,217.1$ & 71.1 & 44.2 & \\
\hline 9 & $47.8,228.1$ & 72.1 & 45.1 & \\
\hline 10 & 48.4 & 73.0 & 46.0 & \\
\hline 11 & $49.6,230.5$ & 75.0 & 47.3 & \\
\hline 12 & $50.5,231.8$ & 75.9 & 48.0 & \\
\hline 13 & $51.0,233.0$ & 76.5 & 48.7 & \\
\hline 14 & 51.6 & 77.0 & 49.2 & \\
\hline 15 & 53.4 & $78.8,84.5$ & 51.5 & \\
\hline 16 & $55.1,235.0$ & $80.0,86.0$ & 52.5 & \\
\hline 17 & $56.3,235.6$ & $81.4,87.0$ & 53.9 & \\
\hline 18 & $57.0,237.4$ & $82.0,87.5$ & 54.5 & \\
\hline 19 & $58.4,245.3$ & $83.5 ?, 88.5$ & 55.3 & \\
\hline 20 & $59.1,246.5$ & & 56.0 & \\
\hline 21 & $59.8,247.0$ & 90.5 & 56.8 & \\
\hline 22 & $60.2,247.7$ & 91.7 & 57.2 & \\
\hline 23 & $60.6,248.5$ & 92.2 & 27.7 & \\
\hline 24 & 61.6 & 93.3 & 59.1 & \\
\hline 25 & 62.1 & 94.0 & 59.7 & \\
\hline 26 & 62.4 & 94.6 & 60.3 & \\
\hline 27 & 63.0 & 94.8 & 60.6 & \\
\hline 28 & 65.7 & 96.0 & 61.6 & \\
\hline 29 & 66.1 & 96.9 & 62.5 & \\
\hline 30 & 67.1 & 98.0 & 63.5 & \\
\hline 31 & 68.0 & 99.1 & 64.6 & \\
\hline 32 & 69.3 & 100.6 & 66.0 & \\
\hline 33 & 72.0 & & 68.2 & \\
\hline 34 & 72.2 & & 68.9 & \\
\hline 35 & 73.2 & & 71.1 & \\
\hline 36 & 74.4 & & 71.6 & \\
\hline 37 & 75.0 & & 72.3 & \\
\hline 38 & 76.0 & & 73.8 & \\
\hline 39 & 76.7 & $103.4 ?$ & 75.0 & \\
\hline 40 & $78.6,263.5$ & 104.8 & 77.2 & \\
\hline 41 & $79.0,265.7$ & 106.1 & 77.8 & \\
\hline 42 & 80.0 & 110.9 & 78.8 & \\
\hline 43 & 80.6 & & 79.2 & \\
\hline 44 & & 112.0 & 80.2 & \\
\hline 45 & $81.4,273.1$ & 113.3 & 81.2 & \\
\hline 46 & $83.5,276.6$ & 116.5 & 83.1 & \\
\hline 47 & $84.0,277.2$ & 117.1 & 83.5 & \\
\hline 48 & $84.9,278.8$ & 118.5 & 84.5 & \\
\hline 49 & $85.0,279.3$ & 119.1 & 85.0 & \\
\hline 50 & $86.1,280.1$ & & 86.1 & \\
\hline 51 & 86.7 & & 87.9 & \\
\hline 52 & 87.2 & & 87.9 & \\
\hline 53 & & & 88.8 & \\
\hline 54 & & & 89.3 & \\
\hline 55 & & & 90.2 & \\
\hline 56 & 91.0 & & 91.0 & \\
\hline 57 & 92.0 & & 93.1 & \\
\hline 58 & $92.5,292.4$ & & 93.8 & \\
\hline 59 & $93.5,293.6$ & & 94.0 & \\
\hline 60 & $94.3,295.0$ & 130.6 & 94.8 & \\
\hline 61 & $96.3,297.6$ & 132.0 & 96.6 & \\
\hline 62 & $96.9,299.2$ & 132.4 & 97.0 & \\
\hline 63 & $97.9,310.0$ & 133.2 & 97.6 & \\
\hline 64 & & 133.7 & 98.2 & \\
\hline 65 & $107.7,330.0$ & 141.2 & $110.0 ?$ & \\
\hline 66 & $112.2,337.8$ & 151.2 & 119.0 & \\
\hline 67 & 115.4 & 153.0 & 120.3 & \\
\hline 68 & 117.2 & 155.0 & 122.0 & \\
\hline 69 & 120.9 & & & \\
\hline 70 & 124.9 & 163.0 & & \\
\hline 71 & 126.3 & 165.0 & & \\
\hline 72 & 419.8 & 185.0 & 143.0 & \\
\hline
\end{tabular}



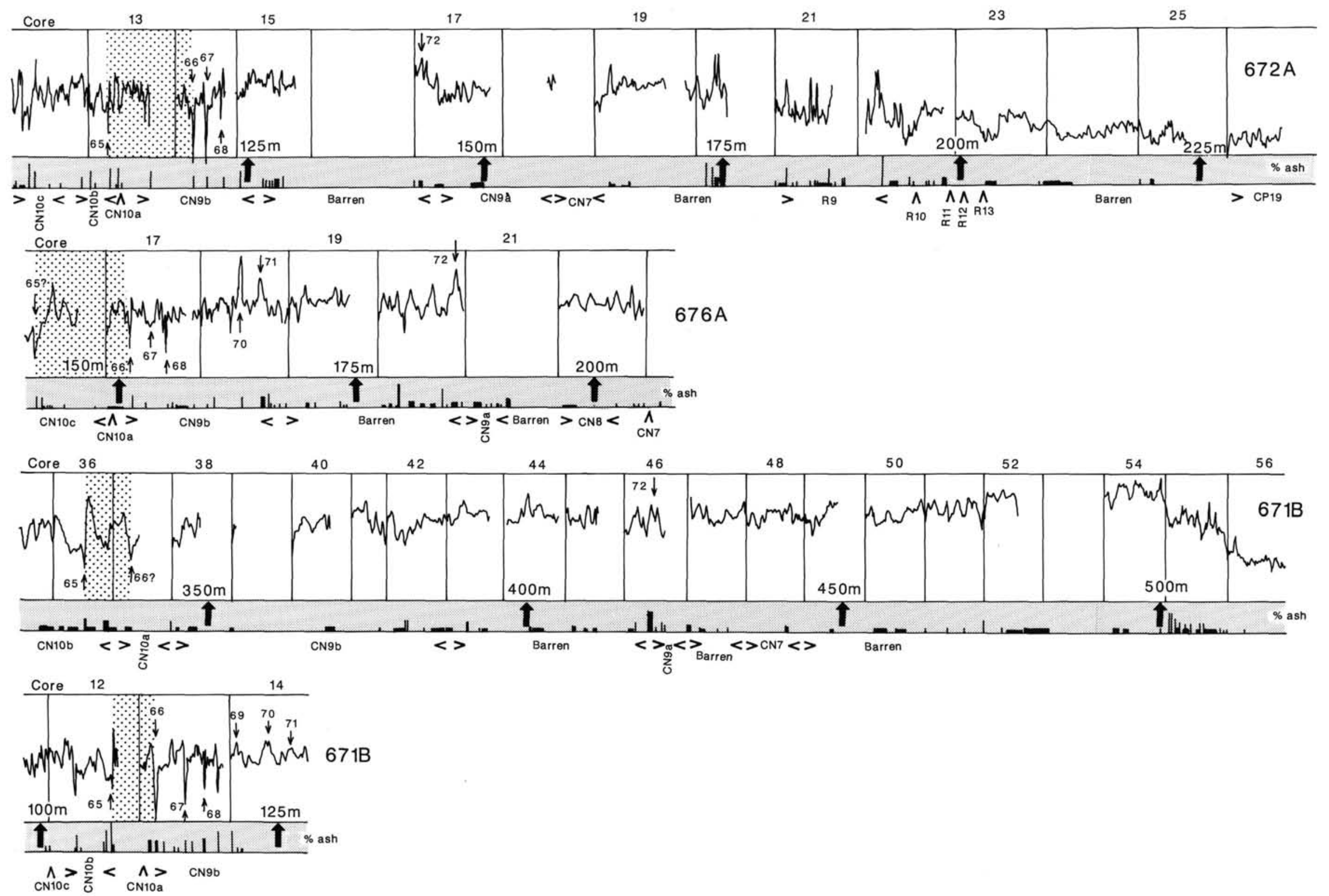

Figure 9. Whole-core magnetic susceptibility data for the Miocene. The nannofossil and radiolarian biostratigraphic zonations are indicated. The correlation of the two peaks B65-B66 between the holes is indicated by a heavy stipple. See Figure 6 for explanation. 